\title{
Apresentação
}

\section{Democracia na América Latina: desafios e perspectivas}

\author{
Débora Messenberg Guimarães \\ Flávia Lessa de Barros \\ Júlio Roberto de Souza Pinto
}

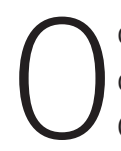

dossiê "Desafios da consolidação democrática na América Latina" é resultado de longa e frutífera parceria entre o Departamento de Sociologia (SOL) e o Centro de Pesquisa e Pós-Graduação sobre as Américas (Ceppac), ambos da Universidade de Brasília, o Centro de Formação, Treinamento e Aperfeiçoamento da Câmara dos Deputados (Cefor) e o Instituto do Legislativo Brasileiro do Senado Federal (ILB). Desde 2007, pesquisadores dessas instituições organizaram três seminários internacionais ("Pensamento e ação política", em 2007; "Vinte anos da Constituição brasileira", em 2008; e "Desafios da consolidação democrática na América Latina", em 2013) e três livros contendo os artigos produzidos para as palestras apresentadas.

Os eventos e as publicações decorrentes - com a participação de especialistas nacionais e internacionais, acadêmicos e políticos - discutem temas relativos à teorização e ao exercício da política contemporânea. Mais importante: representam a abertura da academia e do parlamento brasileiros para a troca de saberes e experiências associada a uma agenda interinstitucional de pesquisa e debate no campo das ciências sociais e da ciência política. Tal empreendimento é norteado por abordagens com perspectivas comparadas e interdisciplinares, no âmbito tanto dos trabalhos individuais como do conjunto das produções envolvidas. Está-se, pois, diante de uma agenda que permite a gratificante observação de interfaces e continuidades entre as várias etapas, abrindo possibilidades futuras que se desdobram com a inclusão de novas temáticas relacionadas, estimulando o prosseguimento da iniciativa.

Este dossiê é o produto direto do último desses seminários, realizado em Brasília de 11 a 13 de junho de 2013. O programa desse simpósio compreendeu temas que vão desde a democracia no século XXI a estratégias de integração na América Latina, passando pela democracia parlamentar, a pluralidade da representação política e as inovações dos mecanismos democráticos. O dossiê se propõe, pois, a contri- 
buir para a reflexão e o debate sobre os potenciais, os limites e os desafios para a consolidação democrática na região e no mundo. Enfatiza-se a necessidade do reconhecimento da relevância da experiência latino-americana na exploração das trajetórias e das grandes tendências de um dos principais metarrelatos da história da modernidade ocidental: a democracia.

Considera-se a importância da experiência latino-americana para o debate sobre os desafios da consolidação democrática tanto por uma perspectiva macro e sistêmica, que abarca as estruturas e as dinâmicas do desenvolvimento do capitalismo e as condições de inserção da região no sistema mundial, como pela ótica das práticas e das interações de atores e instituições que se sobressaem como protagonistas em processos que, de algum modo, influenciam estruturas e dinâmicas e por elas são influenciados. A irrupção das ondas de protestos sociais em inúmeras cidades brasileiras, poucos dias após a conclusão do seminário, observada no contexto maior que envolve fenômenos semelhantes em outros países e regiões do mundo, veio a reforçar a opção por tais perspectivas, de forma inter-relacionada, como uma estratégia acertada no campo das ciências sociais e áreas afins.

O dossiê "Desafios da consolidação democrática na América Latina" é publicado num período significativamente revolvido por grandes marcos na história recente da região e do mundo, que provocam amplas retrospectivas e balanços como condição elementar para se vislumbrar o presente e o futuro. Em diversos países latino-americanos, são rememoradas as décadas de regimes autoritários que assolaram a região, minando direitos civis, políticos, econômicos e culturais e aprofundando desigualdades, injustiças e opressões. São também rememoradas as décadas seguintes, até o presente, que mobilizaram muitos esforços em prol da redemocratização, da maior qualidade da democracia, de sua consolidação e radicalização, os quais redundaram na ascensão das esquerdas em vários países, mediante acirradas disputas entre diferentes projetos políticos de mudança social e de sociedade.

Um debate reativado em tal cenário, com maior centralidade nesses anos de campanha presidencial em alguns países estratégicos na América Latina - e que é transversal no conjunto de artigos reunidos neste dossiê - refere-se à concomitância de processos de redemocratização e consolidação democrática e de processos de resgate e avanço de projetos neoliberais na região. Em geral, as estratégias de desenvolvimento nacional, integração regional e inserção internacional, propugnados e disputados por diversos setores sociais, políticos e econômicos, sofreram e ainda sofrem as tensões entre esses dois movimentos. É preciso notar que estes evoluem em maior ou menor oposição ou complementaridade, conforme as especificidades dos países - variação que também pode ser percebida internamente a cada país, entre determinadas áreas de políticas que aglutinam diferentes atores e insti- 
tuições. Essas disputas e tensões são atualizadas e cada vez mais problematizadas noutro debate relacionado, sobre o "pós-neoliberalismo", ao qual subjazem grandes polissemias, incluindo mesmo o significado de democracia, dos meios e fins dos modelos alternativos.

Não obstante as especificidades dos países latino-americanos, as novas democracias da região tenderam a certo insulamento da política, enfocando sobremaneira sua dimensão administrativa e procedimental. Um traço comum persistente entre vários países na região refere-se à ausência ou à insuficiência de mecanismos para incorporação da multiplicidade de identidades e estratégias apresentadas por novos atores sociais, excluídos ou marginalizados em suas possibilidades de participação e cidadania nos chamados processos de consolidação democrática.

A despeito de certos avanços, consideráveis em alguns casos, as democracias latino-americanas são em grande parte ainda caracterizadas pela falta de correspondência entre as instituições e as práticas sociais, entre a legalidade e a legitimidade e entre a política e a cultura. Ao mesmo tempo, nota-se a falta de correspondência entre Estado e nação, entre território geográfico político-administrativo e identidades histórico-culturais, entre direitos constitucionalmente previstos e direitos realmente vividos (Vilas, 2004; 2011; Dagnino, Olvera e Panfichi, 2006; Ceceña, 2005; Borón, 2003; Quijano, 2004; Stavenhagen, 2001; Casanova, 2002; Garretón, 2002). Como sugerem alguns dos autores aqui reunidos, trata-se de problemáticas ainda bem impregnadas pelo ranço da herança colonial capitalista na América Latina, agravadas pelo imperialismo e pela globalização capitalista neoliberal. Com efeito, esse quadro implica sérios desafios para as esquerdas que ascenderam ao poder desde a última década na região, bem como para outras forças políticas concorrentes, em emergência ou (re)emergência.

Tendo em vista essas grandes tendências, recomenda-se uma leitura transversal do conjunto dos artigos neste dossiê, no intuito de distinguir a perspectiva da historicidade e dos processos macroestruturais para a compreensão da crise da democracia associada à crise do capitalismo e, mais especificamente, da crise do sistema político vinculada à crise do sistema econômico dominante.

Este dossiê procura demonstrar, em suma, a grande riqueza e complexidade da experiência latino-americana para o avanço do debate sobre os desafios da consolidação democrática na contemporaneidade. Procura demonstrar como a experiência latino-americana é emblemática de uma série de urgências. Os artigos reunidos revelam a urgência da discussão sobre os vários sentidos e dimensões de "crise" em curso e da necessidade de alternativas substantivas de seu enfrentamento nos planos estrutural e conjuntural. Os artigos também revelam a urgência de novas formas de construção 
da política, de organização de matrizes sociopolíticas, de equacionamento entre participação e representação, de criação de novos espaços de deliberação e de experimentação de novas utopias. Revelam, ainda, a urgência de desafios a serem enfrentados nas análises sobre os fenômenos envolvidos no campo das ciências sociais e, em especial, na teoria política e na teoria democrática.

No primeiro artigo do dossiê, "Democracia liberal, camino de la autoridad humana y transición al bien vivir", Walter D. Mignolo questiona o que ele considera como "uso acrítico" da palavra "democracia". Após estabelecer uma distinção entre democracia como meio e democracia como fim, defende que o ideal da vida plena, justa e harmoniosa não é alcançável exclusivamente por intermédio da democracia liberal. Para o autor, além de não se poder impor às demais regiões do mundo os meios adotados pela democracia ocidental, estes sequer têm sido idôneos para alcançar os fins por ela mesma preconizados. Mignolo examina a autoridade humana da filosofia política confuciana e o "bem viver" da linguagem do Estado boliviano como meios alternativos ao alcance dos mesmos fins perseguidos pela democracia liberal. Essas vias paralelas têm em comum a percepção do caráter local ou não universal da democracia ocidental, condição necessária, segundo o autor, ao ressurgimento de outras histórias locais, silenciadas pela narrativa (neo)liberal.

O artigo seguinte, "La nueva gramática democrática frente a la integración autónoma latinoamericana y caribeña", de autoria de Jaime Antonio Preciado Coronado, mostra que a experiência da democracia (neo)liberal na América Latina, compreendida como modelo de organização política e sistema de valores anglo-eurocêntrico promovido como global, não logrou os resultados prometidos em termos de estabilidade democrática, desenvolvimento econômico e integração regional. Diante do persistente quadro de desigualdade e exclusão na região, surgem, a partir dos movimentos sociais, projetos políticos com novas gramáticas democráticas relacionadas à integração autônoma latino-americana.

No terceiro artigo, "Pluralidade da representação na América Latina", Maria da Glória Gohn apresenta um amplo painel dos principais movimentos sociais na região, enfocando seus protagonistas, suas demandas e conquistas. A autora procura entender as especificidades do processo histórico associativo latino-americano à luz das transformações globais. Ao final, sugere chaves teórico-metodológicas para a interpretação das recentes manifestações populares de junho de 2013 no Brasil.

O penúltimo artigo, "Representação, crise e mal-estar institucional", de Marco Aurélio Nogueira, dialoga com a chamada "crise da representação" no Estado contemporâneo, consubstanciada na resistência dos parlamentos às crescentes demandas de uma sociedade cada vez mais complexa. O autor relaciona essa crise aos processos 
de desterritorialização e consequente perda de relevância dos Estados nacionais e de tecnicização da política decorrentes da radicalização da modernidade. A despeito desse quadro, Nogueira não acredita que os Estados nacionais ou mesmo os parlamentos deixarão de existir, mas serão forçados a se reorganizarem para assumir novos papéis na sociabilidade explosiva e multifacetada do século XXI.

No último artigo, "Da democracia participativa à pluralidade da representação: breves notas sobre a odisseia do PT na política e na ciência política brasileira", Bruno P. W. Reis argumenta que, conquanto animado por um ideal "participativo" e uma consequente crítica da "democracia representativa", o Partido dos Trabalhadores empenhou-se em respaldar a criação de uma vasta rede de múltiplas formas e instâncias de representação política pelo Brasil afora. Para o autor, é muito difícil sustentar uma contraposição entre representação e participação política. Isso porque o oposto de representação não é participação, mas exclusão, assim como o oposto de participação não é representação, mas abstenção. Essa contraposição só é possível num contraste intuitivo entre política hierárquica, ligada à ideia de representação, e outra estritamente igualitária, não hierárquica, associada à noção de participação. Contudo, segundo Reis, as várias manifestações tópicas de participação sempre revelam uma estrutura relacional que envolve representação de interesses por terceiros e uma distribuição não aleatória de vínculos.

Os textos reunidos neste dossiê indicam, fundamentalmente - e parafraseando Dallmayr (2001) -, que a democracia não é um pacote de regras e procedimentos, ou simplesmente uma entre outras opções igualmente disponíveis de regime. É, antes, resposta a certos desafios e possibilidades históricas. Não é, pois, um processo construído a priori, mas "vivido" à luz das circunstâncias estruturais e valorativas singulares de cada sociedade.

O acirramento da complexificação social na contemporaneidade, ao alimentar crescentes tensões entre as disposições societárias e as instituições políticas, não só impõe às ciências sociais e à ciência política a construção de novos instrumentos teóricos e metodológicos capazes de decodificar os multifacetados processos sociais, como amplia inexoravelmente a relevância pública desses saberes na construção das agendas que conformam e fomentam o debate público.

\section{Referências}

BAUMAN, Zygmunt. Liquid modernity. Cambridge: Polity Press, 2007.

- Em busca da política. Rio de Janeiro: Zahar, 2000. 
Boввı, Norberto. O futuro da democracia. 7. ed. São Paulo: Paz e Terra, 2000.

Borón, Atílio. Estado, capitalismo y democracia en América Latina. Buenos Aires: Clacso, 2003.

CASANOVA, Pablo González. Exploração, colonialismo e luta pela democracia na América Latina. Petrópolis: Clacso; Vozes; LPP, 2002.

CASTELLS, Manuel. Redes de indignação e esperança: movimentos sociais na era da internet. Rio de Janeiro: Zahar, 2013.

CECEÑA, Ana Esther. Hegemonias e emancipações no século XXI; Estratégias de construção de uma hegemonia sem limites. In: CECEÑA, Ana Esther (Org.). Hegemonias e emancipações no século XXI. São Paulo: Clacso, 2005.

DAgnino, Evelina; Olvera, Alberto J.; PANFICHI, Aldo. Introducción: Por otra lectura de la disputa por la construcción democrática en América Latina. In: DAGNINO, Evelina; Olvera, Alberto J.; PANFICHI, Aldo (Orgs.). La disputa por la construcción democrática en la América Latina. México: Fondo de Cultura Económica; Centro de Investigaciones y Estudios Superiores en Antropología Social; Universidad Veracruziana, 2006.

DALLMAYR, F. Para além da democracia fugidia: algumas reflexões modernas e pós-modernas. In SouzA, Jessé (Org.). Democracia hoje: novos desafios para a teoria democrática contemporânea. Brasília: Editora UnB, 2001.

GARRETÓN, Manuel Antonio. La transformación de la acción colectiva en América Latina. Revista de la Cepal, n. 76. Santiago de Chile, Abr. 2002.

GoHn, Maria da Glória. Sociologia dos movimentos sociais. São Paulo: Cortez, 2013.

HONNETH, Axel. Luta por reconhecimento: a gramática moral dos conflitos sociais. São Paulo: Editora 34, 2003.

QuiJano, Aníbal. Colonialidad del poder, eurocentrismo y América Latina. Revista Venezolana de Economía y Ciencias Sociales, v. 10, n. 1. Caracas, Jan.-Abr. 2004, p. 75-97.

Stavenhagen, Rodolfo. La cuestión étnica. México: Colegio de México, Centro de Estudios Sociológicos, 2001.

VILAS, Carlos. Estado y procesos políticos en América Latina. Argentina: Remedios de Escalada; Universidad Nacional de Lanús, 2011.

. Participation, inequality and the whereabouts of democracy. In: CHALMERS, D. et alii. The new politics of inequality in Latin America: rethinking participation and representation. Oxford: Oxford University Press, 2004. 